\title{
Hepatocyte Nuclear Factor 1-Beta
}

National Cancer Institute

\section{Source}

National Cancer Institute. Hepatocyte Nuclear Factor 1-Beta. NCI Thesaurus. Code C70999.

Hepatocyte nuclear factor 1-beta (557 aa, 61 kDa) is encoded by the human HNF1B gene. This protein is a liver-specific transcription factor. Truncated forms of the protein are involved in the pathology of maturity-onset of diabetes, type 5 . 